\title{
SUSCETIBILIDADE MAGNÉTICA: UM INDICADOR DA EVOLUÇÃO PETROLÓGICA DE GRANITÓIDES DA AMAZÔNIA
}

\author{
MARILIA SACRAMENTO DE MAGALHÃES*, ROBERTO DALL'AGNOL*- \\ WILLIAM AUGUST SAUCK**, JOSE GOUVÊA LUIZ***
}

\begin{abstract}
MAGNETIC SUSCEPTIBILITY: A PETROLOGICAL EVOLUTION INDICATOR OF GRANITOIDS FROM AMAZONIA. Magnetic susceptibility (MS) and opaque mineral studies of granitic rocks from Amazonia has led to a better understanding of the relationship between different magnetic characteristics and the processes that occurred during the evolution of these rocks. Tin-mineralized granites such as the Antônio Vicente, Mocambo, Velho Guilherme, Água Boa, Madeira and Pedra Branca massifs have low MS, and their most altered facies, which are tin-specialized, have the lowest MS values. Relatively reducing oxygen fugacity conditions $\left(\mathrm{f}_{\mathrm{O} 2}\right)$, and, to a lesser extent, the origin of these granites from highly differentiated magmatic melts are probably responsible for the lower MS values. Musa (Mu) and Jamon (J) granites have either high MS values or magnetite (Mt) modal contents, which decrease with magmatic differentiation (amphibole facies $\longrightarrow$ biotite facies $\longrightarrow$ leucogranites). High $\mathrm{f}_{\mathrm{O} 2}$ conditions, near the NNO and HITMQ buffers, dominated during the crystallization of these granites. The Cigano Granite and the Rio Maria Granodiorite show the larger distribution of MS values. Oxygen fugacity conditions between NNO and FMQ buffers prevailed during the formation of the Cigano Granite, explaining its magnetic behavior. High MS values in the Rio Maria Granodiorite occur only near the contact with Proterozoic granitic intrusions (Mu and $\mathrm{J}$ granites), due to the formation of metamorphic magnetite, while lower MS values occur in other parts of the
\end{abstract} batholith

Keywords: granitoids, magnetic susceptibility (MS), magnetite, ilmenite, hematite, oxygen fugacity $\left(\mathrm{f}_{\mathrm{O} 2}\right)$, petrological evolution.

\begin{abstract}
RESUMO Estudos de suscetibilidade magnética (SM) e de minerais opacos de rochas graníticas da Amazônia permitiram discutir a relação entre as variações do comportamento magnético e os processos que ocorreram durante a evolução dessas rochas. Os granitos mineralizados em cassiterita, Antônio Vicente, Mocambo, Velho Guilherme, Água Boa, Madeira e Pedra Branca, apresentam SM baixa, sendo que os valores mais baixos de SM ocorrem em suas fácies mais transformadas, especializadas em $\mathrm{Sn}$. Os valores reduzidos de SM dessas rochas podem ser atribuídos às condiç̃es de fugacidade de oxigênio $\left(f_{02}\right)$ relativamente redutoras durante a sua evolução magmática e, em parte, a sua derivação'a partir de líquidos muito evoluídos. Os granitos Musa (Gmu) e Jamon (Gj) apresentam SM elevada, refletindo conteúdos expressivos de magnetita que decrescem, como a SM, no sentido da diferenciação magmática (fácies com anfibólio $\longrightarrow$ fácies a biotita $\longrightarrow$ ) leucogranitos). Estas rochas devem ter se formado em condições de $\mathrm{f}_{\mathrm{O} 2}$ relativamente elevadas, próximas às dos tampões NNO e HITMQ. O Granito Cigano (Gcg) e o Granodiorito Rio Maria (GDrm) apresentam variação ampla de SM. No Gcg, as condições de $\mathrm{f}_{\mathrm{O} 2}$ mais baixas que às do tampão NNO e superiores a FMQ devem ser a causa para este tipo de comportamento magnético. No GDrm, esse tipo de distribuição dos dados magnéticos é conseqüência da neoformação de magnetita nas porções próximas ao seu contato com intrusões graníticas do Proterozóico (Gmu e Gj), uma vez que em porções mais afastadas do contato, a SM é predominantemente mais baixa.
\end{abstract}

Palavras-chave: granitóides, suscetibilidade magnética (SM), magnetita, ilmenita, hematita, fugacidade de oxigênio $\left(\mathrm{f}_{\mathrm{O} 2}\right)$, evolução petrológica.

INTRODUÇ̃̃o Dados de suscetibilidade magnética (SM) têm sido empregados na interpretação geológica de forma contínua, seja a partir de levantamentos aeromagnéticos (Balsley \& Buddington 1958, Speer 1981, Criss \& Champion 1984, Grant 1985, Hattori 1987) ou em estudos de paleomagnetismo (Collinson 1983), seja pela realização de medidas de SM em afloramentos, testemunhos de sondagem ou em amostras-de-mão (Mooney \& Bleiffus 1953 , Henkel 1976, Ishihara 1981, Criss \& Champion 1984, Lapointe et al 1984, 1986). Especificamente, dados de SM têm sido utilizados em estudos de cunho petrológico e metalogenético (Ishihara 1981, Lapointe et al. 1986). Estes autores discutiram a relação entre as variações de comportamento magnético e alguns dos processos que ocorreram durante a evolução de rochas graníticas. A relativa rapidez com que um grande número de medidas de SM pode ser obtido é mais um dos fatores que favorece a sua utilização.

A assinatura magnética de uma rocha está diretamente relacionada ao seu conteúdo de minerais ferromagnéticos, daí a importância de identificar as fases minerais denominadas opacas (Buddington \& Lindsley 1964, Haggerty 1981a, b), nas quais se inclui a magnetita, principal mineral ferromagnético, bem como de determinar os fatores que controlam o equilíbrio dessas fases (Buddington \& Lindsley 1964, Spencer \& Lindsley 1981, entre outros). Recentemente, o termo petrologia magnética (Wasilewski \& Warner 1988, Frost 1991) foi utilizado para denominar estudos de propriedades magnéticas de rochas integrados à petrologia convencional.

Os primeiros estudos, envolvendo dados de SM de granitóides do Cráton Amazônico, foram elaborados

\footnotetext{
* Departamento de Geoquímica e Petrologia - Centro de Geociências - Universidade Federal do Pará (UFPA). Caixa Postal 1611 Belém - Pará - Brasil 66075-900, E-mail: ledsham@unisys.com.br

** Institute for Water Sciences - Western Michigan University Kalamazoo - Michigan - US A - 49008

*** Departamento de Geofísica - Centro de Geociências - Universidade Federal do Pará (UFPA). Caixa Postal 1611 Belém - Pará - Brasil - 66075-900
} 
por DalTAgnol et al. (1988). A partir daí, estudos detalhados foram realizados a fim de verificar as diferenças petrográfícas e geoquímicas observáveis nestas rochas e nas fácies de um mesmo corpo granítico, que podiam estar relacionadas à variação do conteúdo de magnetita e, por sua vez, à variação de SM (Magalhães 1991, Magalhães \& Dall'Agnol 1991, Magalhães \& Dall'Agnol 1992).

Uma discussão integrada dos dados de SM e de minerais opacos será apresentada para os granitos anorogênicos do Proterozóico Inferior-Médio: Cigano, Musa, Jamon, Antônio Vicente, Mocambo e Velho Guilherme, situados na Amazônia Oriental, granitos Água Boa e Madeira, em Pitinga, Amazonas, e do Proterozóico Superior: Granito Pedra Branca, em Rondônia; e de uma porção do granodiorito arqueano Rio Maria, situado na Amazônia Oriental (Fig. 1).

\section{SUSCETIBILIDADE MAGNÉTICA DOS GRANITÓI- DES ESTUDADOS Apresentação dos Dados}

Os dados de suscetibilidade magnética (SM) foram obtidos a partir da elaboração de medidas em amostras-de-mão (Magalhães 1991) com o suscetibilímetro CTU-2, fabricado pela SCINTREX. A SM de cada amostra corresponde ao seu valor médio, obtido a partir da tomada de várias medidas. Todos os valores de SM são apresentados em unidade eletromagnética volumétrica do Sistema Internacional. Uma discussão detalhada da metodologia é apresentada em Magalhães (1991) e de forma sumariada em Magalhães \& Dall'Agnol (1992).

As medidas de SM foram separadas em populações para cada granitóide estudado a partir de gráficos de probabilidade e histogramas de freqüência (Magalhães 1991). Essas informações estão sumariadas na tabela 1 , que mostra as diferenças dos valores de SM obtidos para os diversos granitóides, bem como as relações entre esses dados e as fácies de cada corpo granítico.

Três tipos de comportamento magnético foram observados (Figs. 2 e 3): granitos com SM predominantemente baixa, com SM elevada e aqueles com variação ampla de $\mathrm{SM}$, nos quais uma mesma fácies pode apresentar tanto valores baixos quanto elevados de suscetibilidade (Tab. 1).

No grupo de granitos com SM baixa, ocorrem os maciços estaníferos Antônio Vicente (Gav), Mocambo (Gmo), Velho Guilherme (Gvg), Água Boa (Gab), Madeira (Gmd) e Pedra Branca (Gpb) (Figs. 2 e 3a). Para o Gav, que possui uma amostragem considerável, pôde-se distinguir comportamentos magnéticos distintos das várias fácies que o compõem (Tab. 1). Mais da metade de suas amostras, cerca de $75 \%$, corresponde a valores de SM de fácies com biotita $\left(0,68 \times 10^{-4}\right.$ $\left.-18 \times 10^{14}\right)$, inclusive de suas porções mais transformadas. Os $25 \%$ das amostras restantes possuem SM entre $18 \times 10^{-4}$ e $100 \times 10^{\prime 4}$, apenas uma amostra tem SM igual a $205 \times 10^{-4}$. Dentre as amostras com SM maior do que $40 \times 10^{-4}$ (Tab. 1) destacam-se aquelas em que anfibólio é uma das fases minerais ferromagnesianas.

Os maciços graníticos Musa (Gmu) e Jamon (Gj) correspondem ao grupo de granitos com SM elevada (Figs. 2 e $3 \mathrm{~b}$ ). Tal tipo de comportamento magnético é discutido detalhadamente em Magalhães \& Dall'Agnol (1992). Nesses granitos, os valores compreendidos entre $12,57 \times 10^{-4}$ e $100 \times 10^{-4}$ são observados nas fácies hololeucocráticas (Tab. I). No intervalo de $100 \times 10^{-4}$ a $177 \times 10^{-4}$, predominam as fácies contendo biotita como principal mineral ferromagnesiano. Tais fácies representam estágios intermediários de evolução magmática entre aqueles dos leucogranitos (líquidos mais diferenciados) e das suas fácies com anfibólio e biotita (menos evoluídas). SM superior a $178 \times 10^{-4}$ é observada apenas nas fácies geoquimicamente menos evoluídas (Tab. 1).
O Granito Cigano (Gcg) e o Granodiorito Rio Maria (GDrm) possuem valores de SM distribuídos de forma mais ampla nos diversos intervalos magnéticos apresentados na figura 3c. As fácies que compõem essas duas unidades não apresentam um comportamento magnético uniforme (Tab. $1)$. No caso do Gcg é notável a presença de quase todas as suas fácies, com exceção dos anfibólio-biotita monzogranitos porfiríticos, nas três populações de SM distinguidas (Tab. 1), este é um comportamento muito contrastante em relação aos observados nos granitos discutidos anteriormente. No GDrm, SM de aproximadamente $50 \times 10^{-4}$ pode ser considerada como o limite entre os seus valores baixos e elevados, constatando-se que suscetibilidade relativamente elevada, cerca de $36 \%$ das amostras estudadas, distribui-se nas proximidades do seu contato com os maciços graníticos Musa e Jamon; enquanto as porções afastadas do contato possuem, em geral, SM inferior ao limite citado. Esse aspecto é discutido em detalhe em Magalhães \& Dall'Agnol (1991).

Comparações Considerando os valores de SM observados nos granitos Musa e Jamon como uma referência para comparação entre os comportamentos magnéticos dos três grupos de granitóides discutidos, podemos apresentar o seguinte quadro:

1- O intervalo de SM observado nas fácies hololeucocráticas do Gmu e do Gj $\left(12,57 \times 10^{-4}-100 \times 10^{-4}\right)$, o qual corresponde os valores mais baixos de SM desses granitos, eqüivale aos valores mais elevados do Gav, cerca de $27 \%$ dos seus dados, $55 \%$ e $30 \%$ dos dados do Gcg e do GDrm, respectivamente. Estes três granitóides possuem, isespectivamente, $73 \%, 40 \%$ e $45 \%$ de suas amostragens com SM inferior a $12,57 \times 10^{-4}$ (Tab. 1).

2- $\mathrm{SM}$ comuns às fácies a biotita do $\mathrm{Gmu}$ e do $\mathrm{Gj}$ $\left(100 \times 10^{-4}-178 \times 10^{-4}\right)$ correspondem aos valores mais elevados do Gcg (6\%) e cerca de $13 \%$ daqueles do GDrm, neste caso, estas amostras do GDrm distribuem-se nas proximidades do seu contato com maciços graníticos proterozóicos (Gmu e Gj).

3- SM superiores a $178 \times 10^{-4}$ (Tab. 1) são observadas nas fácies geoquimicamente menos evoluídas desses maciços. O GDrm possui cerca de $13 \%$ dos seus valores mais elevados distribuídos no intervalo $\left(178 \times 10^{-4}-247 \times 10^{-4}\right)$, correspondendo a amostras localizadas em porções próximas do contato com as intrusões graníticas comentadas anteriormente.

GRANITOS COM SM BAIXA O baixo conteúdo de opacos (Tab. 2) e, conseqüentemente, de magnetita (Mt), acarreta os baixos valores de SM dos granitos estaníferos que constituem esse grupo. Para o Gav, que possui uma amostragem considerável, pôde-se distinguir comportamentos magnéticos distintos das várias fácies que o compõem e que refletem a evolução magmática e pós-magmática desse maciço (Tab. 1).

Três domínios faciológicos principais foram observados no Gav (Teixeira \& Dall'Agnol 1991): biotita monzogranitos, porção NE do corpo; biotita sienogranitos, desde termos pouco transformados (BSG) a intensamente transformados (BSIT), porções N, NW, central e SE; e biotitaanfibólio e anfibólio-biotita sienogranitos (BAS e ABS), porções central e SW do maciço. Estas rochas apresentam, em geral, conteúdo de máficos muito reduzido (menos de $5 \%$ ), caracterizando-se principalmente como leucogranitos. No domínio dos BAS-ABS, ocorre, em algumas porções, um enriquecimento relativo de máficos (mais de $5 \%$ ) (Teixeira \& Dall'Agnol 1991).

As fácies mais transformadas do Gav - biotita sienogranitos transformados, BST, e BSIT - apresentam os mais baixos valores de SM (Tab. 1). O principal mineral opaco 


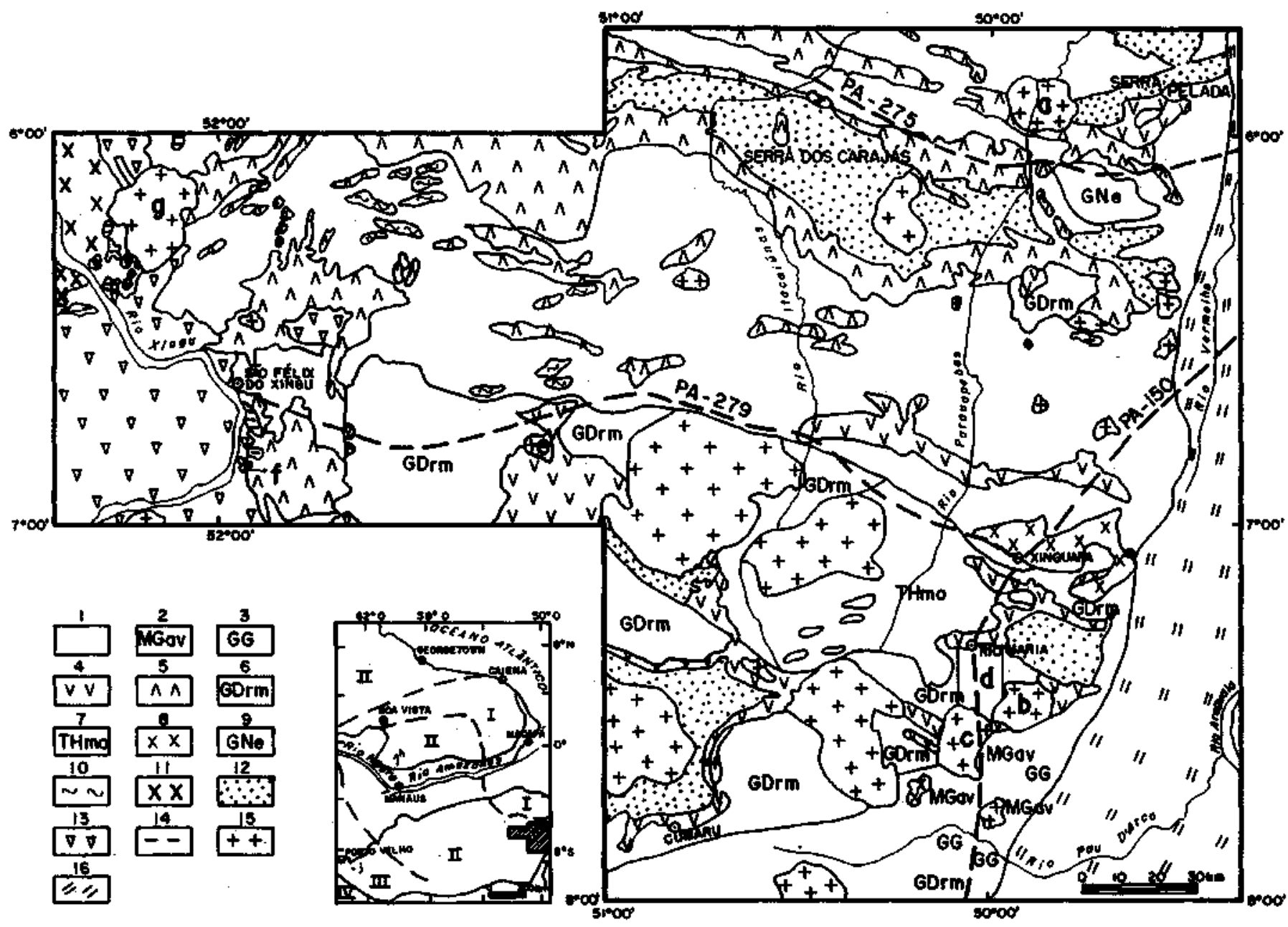

Figura l - Mapa geológico das regiões de Carajás, Rio Maria (DOCEGEO 1988, modificado de acordo com Souza et al. 1990, Althoff et al. 7997, Barros et al. 7992; simplificado) e São Félix do Xingu (Macambira \& Vale no prelo, simplificado de acordo com Hirata et al. 7952, Dall'Agnol et al. 1987), mostrando os granitos Antônio Vicente, Mocambo, Velho Guilherme, Musa, Jamon, Cigano e Granodiorito Rio Maria. No encarte é fornecida a disposição dos granitos estudados (incluindo os granitos Água Boa, Madeira e Pedra Branca) nas províncias do Cráton Amazônico (cf. Teixeira et al. 1989). Legenda: 1. Complexo Xingu, rochas gnáissicas tonalíticas e granodioríticas; 2. Metatonalito Gnáissico Arco Verde; 3. Granito Guarantã; 4. seqüências do tipo greenstone belt; 5. seqüências metavulcano-sedimentares; 6. Granodiorito Rio Maria; 7. Trondhjemito Mogno; 8. Leucomonzogranitos; 9. Gnaisse Estrela; 10. Granito Plaque; 11. Granito Parauari; 12. Grupo Rio Fresco, sedimentospeliticos, elásticos e químicos anquimetamórficos; 13. Grupo Uatumã, rochas vulcânicas andesíticas, dacíticas e riolíticas; 14. Formação Triunfo, arenitos; 15. granitos anorogênicos; 16. Faixa de Dobramentos Araguaia. Províncias: I Maroni-Itacaiúnas, II Amazonia Central, III Rio Negro-Juruena, IV Rondoniana. Granitóides estudados: a. Cigano, b. Jamon, c. Musa, d. porção estudada do Granodiorito Rio Maria, e. Velho Guilherme, f. Mocambo, g. Antônio Vicente, h. Agua Boa, i. Madeira, j. Pedra Branca

Figure 1 - Geologic map of Carajás, Rio Maria (DOCEGEO 1988, modified after Souza et al. 1990, Althoff et al. 1991, Barros et al. 1992; simplified), and Sao Felix do Xingu regions (Macambira \& Vale in press, simplified after Hirata et al. 1982 and Dall'Agnol et al. 1987), showing the Antonio Vicente, Mocambo, Velho Guilherme, Musa, Jamon and Cigano granites, and Rio Maria Granodiorite. The small sketched map presents the distribution of the studied granites (including Agua Boa, Madeira and Pedra Branca granites) in the Amazonian Craton provinces (Teixeira et al. 1989). 1. Xingu Complexe, tonalitic and granodioritic gneissic rocks; 2. Arco Verde Gneissic Metatonalite; 3. Guarantã Granite; 4. Greenstone belt sequences; 5. metavolcanic and metasedimentary sequences; 6. Rio Maria Granodiorite; 7. Mogno Trondhjemite; 8. Leucomonzogranites; 9. Estrela Gneiss; 10. Plaque Granite; 11. Parauari Granite; 12. Rio Fresco Group, anchimetamorphic pelitic, clastic and chemical sediments; 13. Uatuma Group, andesites, dacites and rhyolites; 14. Triunfo Formation, arenites; 15. anorogenic granites; 16. Araguaia fold belt. Provinces: I Maroni-Itacaiunas, II Central Amazonia, III Rio Negro-Juruena, IV Rondonian. Studied granitoids: a. Cigano, b. Jamon, c. Musa, d. studied area of the Rio Maria Granodiorite, e. Velho Guilherme, f. Mocambo, g. Antonio Vicente, h. Agua Boa, i. Madeira, j. Pedra Branca

presente nessas rochas é ilmenita (Ilm). Por sua vez, as fácies com anfibólio apresentam SM relativamente mais elevada e são rochas geoquimicamente menos evoluídas que os biotita sienogranitos (BS). Seus minerais opacos são, em parte, Mt. Amostras de BS pouco transformados (BSG) possuem valores de SM intermediários aos dos dois grupos comentados anteriormente (Tab. 1). Seus minerais opacos são, principalmente, Mt e Ilm (Tab. 2). O menor conteúdo de Mt dos BSG, comparativamente com as proporções desse mineral nas fácies com anfibólio, e a desestabilização de Mt devem ser os fatores que proporcionam valores de SM inferiores àqueles das fácies com anfibólio.

$\mathrm{Na}$ porção do Gav com valores de SM mais baixos, ocorrem as áreas mineralizadas em cassiterita. A presença 
Tabela 1- Sumário dos dados de suscetibilidade magnética (SM) dos granites Antônio Vicente, Musa, Jamon, Cigano e do Granodiorito Rio Maria

Table 1 - Summary of magnetic susceptibility (MS) data from Antonio Vicente, Musa, Jamon and Cigano granites, and Rio Maria Granodiorite

\begin{tabular}{|c|c|c|c|c|}
\hline GRANITOOIDES & POPULAÇŐES & $\begin{array}{c}\text { INTERVALOS de SM } \\
\left(\mathrm{X} 10^{-1} \mathrm{SI}\right)\end{array}$ & $\begin{array}{c}\text { PROPORÇŐES DOS } \\
\text { DADOS (\%) }\end{array}$ & FÁCIES \\
\hline \multirow{5}{*}{$\begin{array}{c}\text { Antônio } \\
\text { Vicente } \\
\text { Gav }\end{array}$} & A & $0,68-1,0$ & 20 & BSIT $^{*}$ e BST \\
\hline & B & $1,0-2,0$ & 30 & $\begin{array}{l}\text { BSIT, BST } \\
\text { BM e MCM }\end{array}$ \\
\hline & C & $2,0-6,3$ & 15 & $\begin{array}{l}\text { BSIT, BSG } \\
\text { BM e MCM }\end{array}$ \\
\hline & D & $6,3 \cdot 40,0$ & 20 & $\begin{array}{l}\text { BSG*, BST } \\
\text { BM e MCM }\end{array}$ \\
\hline & $\mathbf{E}$ & $40,0-205$ & 15 & $\begin{array}{l}\text { BAS, ABS* e } \\
\text { BSG }\end{array}$ \\
\hline \multirow{3}{*}{$\begin{array}{l}\text { Musa } \\
\text { Gmu }\end{array}$} & $\mathbf{A}$ & $13-71$ & 20 & $\begin{array}{l}\text { leucogranitos } \\
\text { (LM, LS, MCS) }\end{array}$ \\
\hline & $\mathbf{B}$ & $71-178$ & 50 & $\begin{array}{l}\text { ABS, BM, } \\
\text { leucogranitos*1 }\end{array}$ \\
\hline & C & $178-322$ & 30 & $\begin{array}{l}\text { BAM }{ }^{*}, \text { ABM }^{*} \\
\text { e ABSE }\end{array}$ \\
\hline \multirow{3}{*}{$\underset{G j}{\operatorname{Jamom}}$} & $A$ & $23-40$ & 15 & $\begin{array}{l}\text { leucogranitos } \\
\text { (LM) }\end{array}$ \\
\hline & $\mathbf{B}$ & $40-178$ & 55 & $\begin{array}{l}\mathrm{ABM}, \mathrm{BMH}^{* 1} \mathrm{e} \\
\mathrm{LM}^{* 1}\end{array}$ \\
\hline & $\mathrm{C}$ & $178-232$ & 30 & BAME e ABME \\
\hline \multirow{3}{*}{$\begin{array}{c}\text { Cigano } \\
\text { Gcg }\end{array}$} & A & $0,57-5$ & 20 & $\begin{array}{l}\text { ABMSG, BS e } \\
\text { MT*2 }\end{array}$ \\
\hline & B & $5-32$ & 40 & $\begin{array}{l}\text { ABMSG, ABMSP } \\
\text { BMS*, MT }{ }^{* 2}\end{array}$ \\
\hline & $\mathrm{C}$ & $32-175$ & 40 & $\begin{array}{l}\text { ABMSG*, ABMP* } \\
\text { BMS e MT*2 }\end{array}$ \\
\hline \multirow{4}{*}{$\begin{array}{l}\text { Granodiorito } \\
\text { Rio Maria } \\
\text { GDrm }\end{array}$} & A & $1 \cdot 4$ & 35 & $\begin{array}{l}\text { BGd*, HBGd* } \\
\text { BHGd e HBM }\end{array}$ \\
\hline & $\mathbf{B}$ & $4-50$ & 30 & $\begin{array}{l}\text { BGd, HBGd* } \\
\text { BHGd e BM }\end{array}$ \\
\hline & $\mathrm{C}$ & $50-200$ & 25 & HBGd e BHGd* \\
\hline & D & $200-247$ & 10 & BHGd e BHM \\
\hline
\end{tabular}

SM: suscetibilidade magnética

* fácies que se destacam nos referidos intervalos, *1 fácies dominantes no limite inferior do intervalo. *2 fácies distribufdas de forma regular nos intervalos mencionados

A: anfibólio, B: biotita, H: homblenda, E: equigranular, G: grosso, H: heterogranular (Gj), P: porfirítico, MC: micro, GD: granodiorito, M: monzogranito, S: sienogranito, T: transformado, I: intensamente.

de rochas intensamente transformadas nessa área e até mesmo a identificação de greisens (Teixeira \& Dall' Agnol 1991) mostram a correlação das transformações tardi a pós-magmáticas aos processos de transporte, concentração e precipitação de $\mathrm{SnO}_{2}$ no maciço. Os processos secundários conduziram à acumulação da cassiterita nos aluviões.

As condições de $\mathrm{f}_{\mathrm{O} 2}$ das fusões silicáticas a partir das quais estas rochas foram geradas, devem ter sido determinantes na formação da assembléia mineralógica observada, inclusive de seus minerais opacos. Entretanto, os baixos valores de SM dos granitos desse grupo (Fig. 3a) podem ser, em parte, devidos também às transformações tardi a pósmagmáticas, que devem ter funcionado como desestabilizadoras da magnetita formada nos estágios mais precoces da diferenciação magmática, bem como decorrência do caráter muito evoluído dos líquidos a partir dos quais estes granitos foram gerados. De acordo com Taylor \& Wall (1992), o Sn é mais abundante nas rochas derivadas de magmas cujas condições de $\mathrm{f}_{\mathrm{O} 2}$ são menos oxidantes do que aquelas mais freqüentes durante a cristalização de magmas graníticos.

Os dados de SM e mineralogia dos opacos desses granitos revelam que, além das suas similaridades petrográficas 


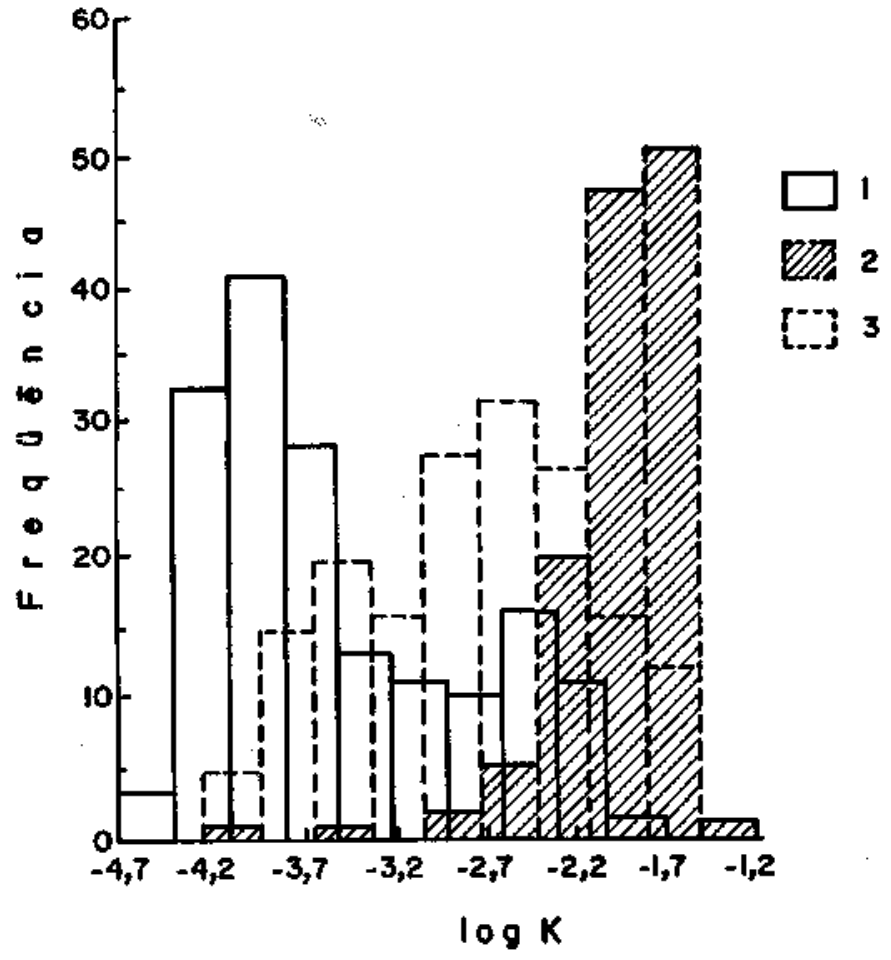

Figura 2 - Histogramas de freqüencia dos conjuntos de dados de suscetibilidade magnética $(K)$ dos granitos estaniferos Antônio Vicente, Mocambo, Velho Guilherme, Agua Boa, Madeira e Pedra Branca, 1. dos granitos Musa e Jamon, 2. do Granito Cigano e do Granodiorito Rio Maria, 3. K em unidade eletromagnética volumétrica do Sistema Internacional

Figure 2 - Comparison of magnetic susceptibility (K) frequency histograms of tin-mineralized granites: Antonio Vivente, Mocambo, Velho Guilherme, Água Boa, Madeira and Pedra Branca, 1. Musa and Jamon granites, 2. Cigano Granite and Rio Maria Granodiorite, 3. K in SI units

e geoquímicas assinaladas por outros autores (Dall'Agnol et al 1987), os mesmos devem ter sido derivados de magmas que evoluíram sob condições de $\mathrm{f}_{\mathrm{O} 2}$ análogas e relativamente baixas, se comparadas aos demais granitos discutidos nesse trabalho. Esse aspecto deve ter sido determinante na geração das mineralizações estaníferas associadas a esses granitos.

GRANITOS COM SM ELEVADA Os granitos Musa (Gmu) e Jamon (Gj) apresentam SM predominantemente elevada (Magalhães \& Dall'Agnol 1992) (Tab. 1 e Fig. 3b). A distribuição dos dados de SM em histogramas de freqüência e em gráfico de probabilidade permitiu separar para cada maciço, populações com comportamento magnético distinto. A população com valores mais elevados corresponde principalmente aos monzogranitos com anfibólio, rochas geoquimicamente menos evoluídas; enquanto valores mais baixos correspondem aos leucogranitos, formados mais tardiamente no processo de evolução magmática. No intervalo intermediário de SM, destacam-se biotita granitos, rochas que se encontram geoquimicamente entre os granitos enriquecidos em anfibólio e os leucogranitos (Tab. 1).

Tanto no Gmu quanto no $\mathrm{Gj}$, existem correlações claras entre os valores de SM e os conteúdos modais de minerais, ressaltando-se as correlações positivas entre SM e opacos, SM e anfibólio e a correlação negativa entre SM e clorita (Magalhães \& Dall'Agnol 1992). Os conteúdos modais de opacos e anfibólio são mais elevados nas fácies menos evoluídas desses granitos, enquanto que nas rochas mais transformadas, em que a desestabilização da associação mineral primária, inclusive de magnetita, é mais intensa, a presença de clorita, fase deutérica, é marcante. Conseqüentemente, ocorre a diminuição dos valores de SM conforme o conteúdo de clorita aumenta. Isto demonstra que os valores de SM refletem a evolução das rochas em questão.

Estes granitos são ricos em magnetita (Mt) como atestam seus valores de $\mathrm{SM}$ e as observações de secções polidas. Além de Mt (Prancha Ia, b, c), outro mineral opaco comum nestas rochas é ilmenita (Ilm), a qual pode ser texturalmente classificada em quatro tipos (Magalhães \& Dall'Agnol 1992, Dall'Agnol et al 1995): composite (C), patch (P), trellis $(\mathrm{T})$ - ilmenitas associadas a $\mathrm{Mt}$ - e cristais individuais (I) (Tab. 2 e Prancha $1 \mathrm{a}, \mathrm{b})$.

Âs relações texturais das Ilm I e C (Prancha Ia, b) com outros constituintes minerais (cf. Magalhães \& Dall'Agnol 1992) e suas composições químicas (Dall'Agnol et al. 1995) sugerem sua formação precoce, cristalização nos estágios iniciais de formação desses granitos. Durante a evolução magmática, Ilm I foi parcialmente desestabilizada, sendo substituída por titanita (Prancha $1 \mathrm{~b}$ ), como sugerem os seus limites irregulares quando bordejada por este mineral.

As Ilm T, por sua vez, são secundárias. Formaram-se no estágio subsolidus, como sugere a associação Mt + Ilm T (Prancha $1 \mathrm{a}, \mathrm{b}$ ). Os cristais de Mt originalmente deveriam ser titanomagnetitas, que começaram a ser formadas no estágio inicial da cristalização magmática, como os cristais de Ilm I e C. Devido ao processo de exsolução-oxidação (Buddington \& Lindsley 1964), as titanomagnetitas transformaram-se em Mt puras associadas a lamelas de Ilm. As composições químicas e texturas da Ilm P indicam igualmente sua formação secundária e em equilíbrio com Ilm T (Dali' Agnolef ai 1995).

Outras transformações, comuns no estágio subsolidus e posteriores ao processo de exsolução-oxidação, são a martitização de Mt e oxi-hidratação de Mt e pirita, levando à formação de goethita. Pirita também se formou precocemente, no entanto, ocorre em proporções muito pequenas nestas rochas.

O conteúdo expressivo de minerais opacos, valores de até $2 \%$ nas fácies menos evoluídas, e os valores mais elevados de $\mathrm{Mt}$, bem como as razões $\mathrm{Fe}_{2} \mathrm{O}_{3} / \mathrm{FeO}$ em torno de um $(1,0)$ (Dall'Agnol et al 1988, Gastai 1988), permitem classificar as rochas estudadas como granitos da série a magnetita (Ishihara 1977, 1981).

Dados de $\mathrm{f}_{\mathrm{O} 2}$ apresentados para o Gj por Dall'Agnol et al (1995), em conjunto com as evidências discutidas em Magalhães \& Dall'Agnol (1992), como por exemplo a associação mineral magnetita-titanita-quartzo (Wones 1989), comum nestes granitos, levam a conclusão de que estes cristalizaramse em condições de $\mathrm{f}_{\mathrm{O} 2}$ relativamente elevadas, possivelmente próximas àquelas dos tampões NNO e HITMQ (Whalen \& Chappell 1988, Dall'Agnol et al 1995).

\section{GRAIMITÓIDES COM VARIAÇÃO AMPLA DE SM}

O Granito Cigano (Gcg) e o Granodiorito Rio Maria (GDrm) distinguem-se petrográfica e geoquimicamente. Pode-se destacar que o Gcg é um maciço anorogênico de natureza alcalina (Dall'Agnol et al 1994) gerado no Proterozóico Inferior (Gonçalez et al 1988, Machado et al 1988), enquanto o GDrm constitui um batólito de idade arqueana, geoquimicamente cálcio-alcalino, metamorfisado na fácies xisto-verde (Medeiros \& Dall'Agnol 1988). Entretanto, quanto à distribuição de seus valores de SM, estas rochas assemelham-se (Fig. 3c).

Granito Cigano Este maciço é constituído por fácies monzograníticas e sienograníticas com anfibólio e biotita, apenas com biotita e por fácies monzogranítica hololeu- 


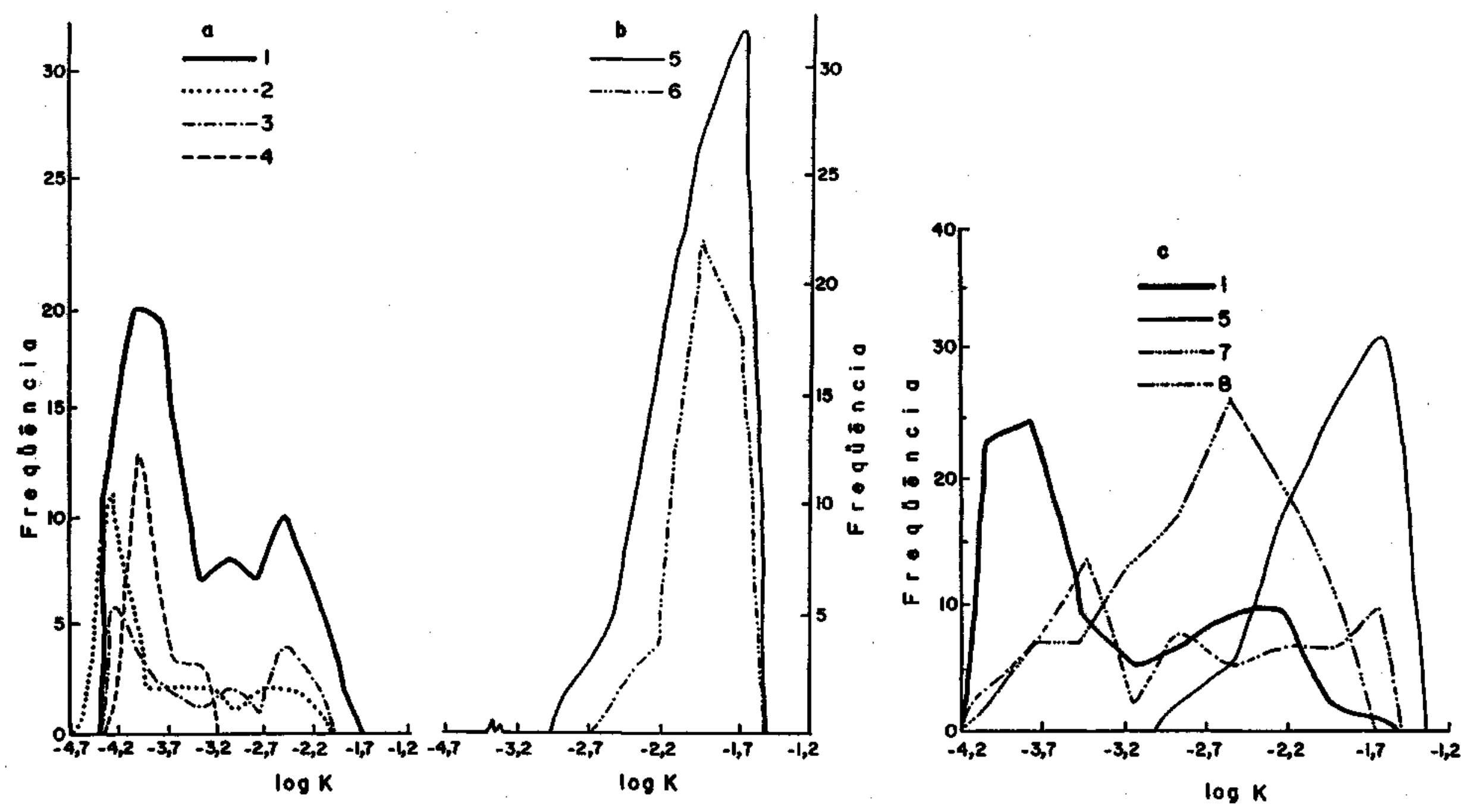

Figura 3 - Polígonos de freqüência referentes aos dados de suscetibilidade magnética (K) (a) dos graniíos estaníferos Antônio Vicente (1), Agua Boa (2), Madeira (3) e Pedra Branca (4); (b) dos granitos Musa (5) e Jamon (6); (c) dos granitos Cigano (7), Musa (5), Antônio Vicente (1) e do Granodiorito Rio Maria (8). K em unidade eletromagnética volumétrica do Sistema Internacional

Figure 3 - Comparison of magnetic susceptibility (K) frequency polygon of (a) tin-mineralized granites: Antonio Vicente (1), Agua Boa (2), Madeira (3) and Pedra Branca (4); (b) Musa (5) and Jamon (6) granites; (c) Cigano (7), Musa (5) and Antonio Vicente (1) granites, and Rio Maria Granodiorite (8). K in SI units 
Tabela 2 - Principais aspectos dos minerais opacos dos granitos Antônio Vicente, Musa, Jamon, Cigano e do Granodiorito Rio Maria

Table 2 - Main aspects of opaque minerals of Antonio Vicente, Musa, Jamon and Cigano granites, and Rio Maria Granodiorite

\begin{tabular}{|c|c|c|c|c|c|}
\hline \multicolumn{2}{|c|}{$\begin{array}{l}\text { MINERAIS GRANITOIDES } \\
\text { OPACOS }\end{array}$} & $\begin{array}{c}\text { ANTONIO VICENTE } \\
\text { Gav }\end{array}$ & $\begin{array}{cc}\text { MUSA } & \text { JAMON } \\
\text { Gmu } & \text { Gj }\end{array}$ & $\begin{array}{l}\text { CIGANO } \\
\text { Geg }\end{array}$ & $\begin{array}{l}\text { RIO MARIA } \\
\text { GDrm }\end{array}$ \\
\hline \multicolumn{2}{|c|}{$\begin{array}{l}\text { Magnetita primária } \\
\text { (TMt original) }\end{array}$} & $\begin{array}{l}\text { comum nas faceis } \\
\text { com anf. e em al- } \\
\text { gumas amostras } \\
\text { de BSO e BST }\end{array}$ & abundante & variável & $\begin{array}{l}\text { comum } \\
\text { (Mt pura) }\end{array}$ \\
\hline \multicolumn{2}{|c|}{ Magnetita secundária } & & & & $\begin{array}{l}\text { contato com } \\
\text { Gmu e Gj }\end{array}$ \\
\hline \multirow{3}{*}{ Ilmenita } & $\mathbf{I}$ & $\begin{array}{l}\text { comum em todas as } \\
\text { fáceis }\end{array}$ & \multirow{2}{*}{$\begin{array}{l}\text { mais abun- } \\
\text { dantes nos } \\
\text { monzogra- } \\
\text { nitos }\end{array}$} & $\begin{array}{l}\text { ABMG } \\
\text { ABMP e } \\
\text { MT }\end{array}$ & \multirow{3}{*}{ ausentes } \\
\hline & $\begin{array}{l}\mathbf{C} \\
\mathbf{T}\end{array}$ & $\begin{array}{l}\text { faceis com anf. } \\
\text { BSG e BST }\end{array}$ & & $\begin{array}{l}\text { comuns } \\
\text { em todas } \\
\text { as fácies }\end{array}$ & \\
\hline & $S$ & BS & $\begin{array}{l}\text { rara ou } \\
\text { ausente }\end{array}$ & $\begin{array}{l}\text { rara ou } \\
\text { ausente }\end{array}$ & \\
\hline \multicolumn{2}{|l|}{ Hematita } & comum nas fáceis & comum & comum & comum \\
\hline \multicolumn{2}{|l|}{ (martita) } & $\begin{array}{l}\text { com anf. e em al- } \\
\text { guns BSG e BST }\end{array}$ & & & \\
\hline \multicolumn{2}{|l|}{ Goethita } & rara & rara & rara & rara \\
\hline \multicolumn{2}{|l|}{ Pirita } & rara & rara & rara & rara \\
\hline \multicolumn{2}{|l|}{ Conteúdo } & $\mathrm{Tr} \cdot 0,7 \%$ & $\operatorname{Tr}-2 \%$ & $\operatorname{Tr} \cdot 1 \%$ & $\mathrm{Tr}-2 \%$ \\
\hline
\end{tabular}

TMt: titanomagnetita. Mt: magnetita. I: ilmenita em cristais individuais. C: ilmenita Composite. T: ilmenita trellis. S: ilmenita sandwich, anf e A: anfibólio. B: biotita. M: monzogranito. S: sienogranito. G: grosso. P: porfirítico. T: transformado

cocrática (Gonçalez et al. 1988). Esta última encontra-se bastante transformada por soluções deutéricas, as quais devem ter agido como desestabilizadoras dos minerais opacos. Por outro lado, nas fácies mais enriquecidas em minerais ferromagnesianos, os minerais opacos encontram-se mais preservados.

Apesar de ser um granito com magnetita, este maciço evoluiu de uma forma claramente diferente daquela do Gmu e do $\mathrm{Gj}$, como demonstram a ampla distribuição de seus valores de SM (Tab. 1), sem predominância de uma determinada fácies em um intervalo magnético específico; as transformações tardi a pós-magmáticas relativamente mais intensas que ocorreram em algumas de suas fácies (biotita monzogranitos, BM e monzogranitos transformados, MT); e as suas composições químicas em rocha total e de seus minerais ferromagnesianos (Dall'Agnol et al. inédito), relativamente enriquecidas em Fe se comparadas com aquelas do Gmu e do Gj.

Espectros analíticos obtidos em microscópio eletrônico de varredura (MEV) sugerem que a composição da magnetita (Mt), dos cristais mais desenvolvidos desse mineral, é bastante pura. Esses cristais de $\mathrm{Mt}$, como nos $\mathrm{Gmu}$ e $\mathrm{Gj}$, deviam ser originariamente titanomagnetitas, que no estágio subsolidus transformaram-se em Mt + Ilmenita trellis (Ilm T). Outro aspecto importante neste granito, diferente daquele dos maciços Musa e Jamon, é a abundância de cristais de Mt de dimensões reduzidas inclusos nos minerais ferromagnesianos, os quais, como comentado anteriormente, são ricos em Fe,

Além de Mt e Ilm T, ocorrem também Ilm I, C e P, pinta e goethita (Tab. 2 e Prancha $1 \mathrm{~d}$, e, $f$ ). A formação de Ilm neste maciço foi expressiva e os seus vários tipos texturais refletem, tal como no caso dos granitos Musa e Jamon, diferentes estágios da evolução magmática. Deve-se ressaltar que a formação apenas de Ilm em amostras da porção sul do maciço sugere que condições de $\mathrm{f}_{\mathrm{O} 2}$ diferentes daquelas presentes durante a evolução dos granitos Musa e Jamon e das demais fácies do Gcg existiram localmente. Com base em dados geoquímicos, Dall'Agnol et al. (inédito) estimam fugacidades de oxigênio, possivelmente, inferiores às relacionadas a NNO, contudo, superiores às do tampão FMQ durante a formação dessas rochas.

Quanto às transformações observadas nos minerais opacos, podem ser ressaltadas a substituição de cristais de Mt por minerais ferromagnesianos (clorita e epídoto), que é facilitada devido ao fraturamento da Mt, e a formação de titanita às expensas das lamelas de Ilm. Além disso, a martitização, transformação dos cristais de Mt em hematita, é expressiva, em particular nas fácies a biotita e nos monzogranitos transformados. Essas transformações sugerem um aumento relativo de $\mathrm{f}_{\mathrm{O} 2}$ durante os processos citados.

As condições de $\mathrm{f}_{\mathrm{O} 2}$ são o fator determinante no comportamento magnético do Gcg, uma vez que esta variável está 
diretamente relacionada aos processos de formação dos minerais opacos. Logo, as diferenças de comportamento em termos de SM entre o Gcg e os granitos Musa e Jamon devem ser, em parte, decorrentes dos processos evolutivos diferentes experimentados por estes maciços. A natureza mais alcalina do magma gerador do Gcg (Dall'Agnol et al. inédito) pode ser uma das causas das diferenças assinaladas entre essas rochas.

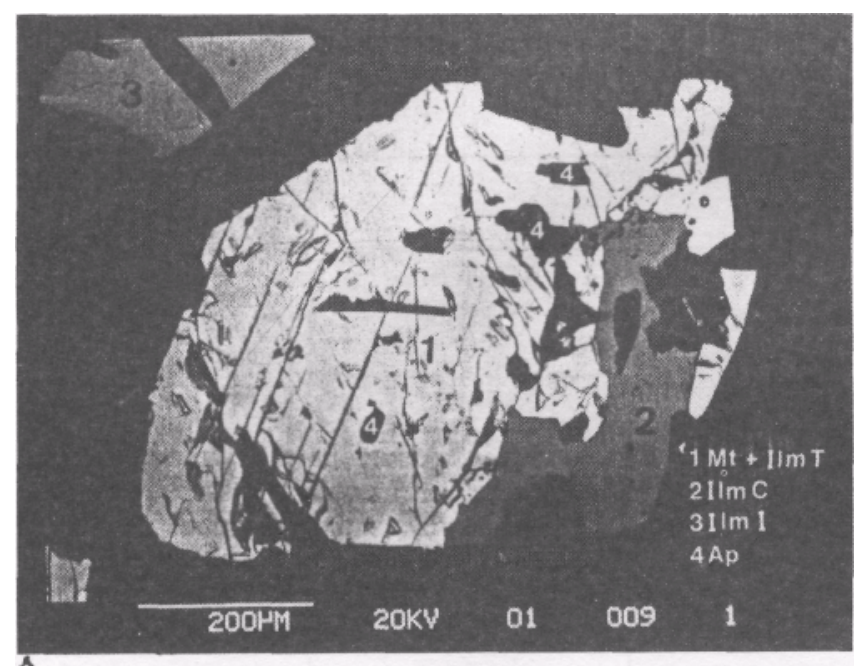

A

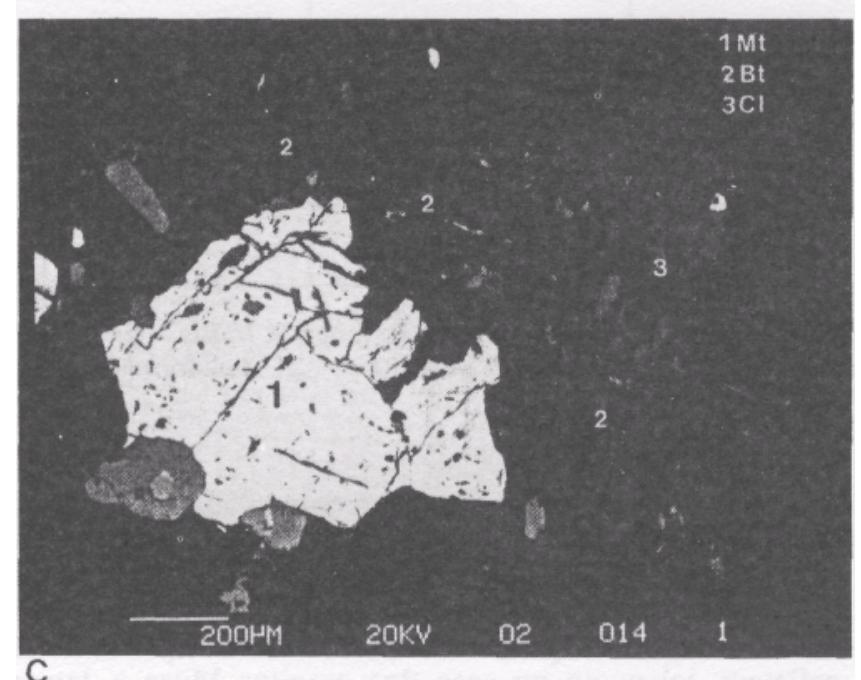

Granodiorito Rio Maria Este granitóide possui valores de SM predominantemente baixos. Exceção a esse tipo de comportamento magnético é observada nas proximidades do contato dessa unidade com granitos do Proterozóico ( $\mathrm{Gmu}$ e $\mathrm{Gj}$ ), onde os valores de SM correspondentes a biotita-hornblenda granodioritos (BHGd), hornblendabiotita granodioritos (HBGd) e hornblenda-biotita monzogranitos são elevados (Magalhães \& Dall'Agnol 1991). Vá-

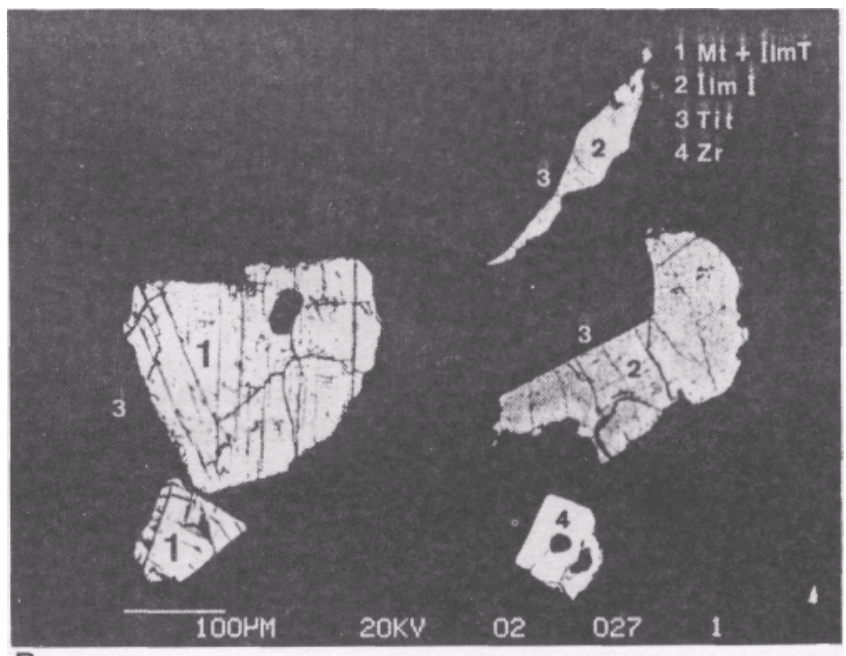

B

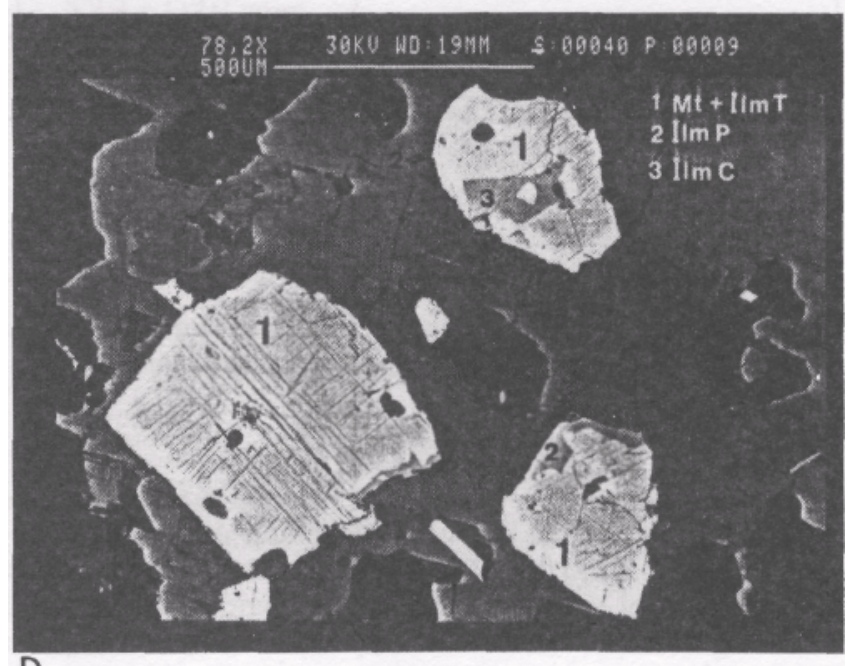

D

Pranchas - Imagens de elétrons retrodifusos obtidas em microscópio eletrônico de varredura (MEV), mostrando aspectos texturais de minerais opacos dos granitos Jamon e Cigano. Mt: magnetita, Ilm: ilmenita, Ap: apatita, Tit: titanita, Zr: zircão, B t: biotita, Cl: clorita. Granito Jamon: amostras (a) CREMU 78A e (b) HZR 752, anfibólio-biotita monzo granitos, e (c) amostra HZR 751B , leucomonzogranito. Granito Cigano: (d) amostra ECR CG 40, anfibólio-biotita monzogranito grosso, (e) amostra ECR CG 34C, anfibólio-biotita monzogranito porfirítico e (f) amostra ECR CG 27R, monzogranito transformado. Prancha a. Cristal de titanomagnetita primária transformada em intercrescimentos de Mt (cinza-claro) e Ilm trellis (T, lamelas escuras) através do processo de exsolução-oxidação. A Mt contém inclusões de Ap (preta) e está associada a Ilm composite (C, cristal cinza-escuro). Vê-se, ainda, no alto à esquerda, um cristal individual de Ilm (I), b. Cristais de Mt (cinzaclaro) intercrescidos com Ilm trellis (T, lamelas escuras) e cristais individuais de Ilm (I, cinza-escuro), parcialmente transformados em Tit (cinza mais escuro). Observa-se, ainda, cristal automórfico de Zr (branco), que, como os minerais opacos, encontra-se associado aos minerais ferromagnesianos. c. Cristal de Mt associado a Bt oxidada ou parcialmente cloritizada e a Cl. $d$. Cristais de Mt (cinza-claro) associados a Ilm trellis ( $T$, lamelas escuras), patch (P, porções irregulares na borda da Mt) e composite (C, cristal subédrico)

Plates- Textural aspects of oxide minerals of the Jamon and Cigano granites (scanning electron microscopy — SEM, back scattered images). Mt: magnetite, Ilm: ilmenite, Ht: hematite, Ap: apatite, Tit: titanite, Zr: zircon, Bt: biotite, Cl: chlorite. Jamon Granite: (a) and (b), CREMU 78A and HZR 752, amphibole-biotite monzogranites; (c) HZR 75IB, leucomonzogranite. Cigano Granite: (d) ECR CG 40, amphibole-biotite coarse monzogranite; (e) ECR CG 34C, amphibolebiotite porphiritic monzogranite; (O ECR CG 27R, altered monzogranite. Plate 1 a. Primary titanomagnetite crystal transformed into Mt (light gray) and trellis (T) Ilm (dark gray lamellae) due to oxidation-exsolution. Mt including Ap (black) and associated to composite (C) Ilm (dark gray), and also, individual (I) Ilm crystal, b. Mt-Ilm intergrowth (Mt + Ilm T), and individual (I) Ilm crystals (dark gray) destabilized by Tit. Automorphic crystal of Zr (white) are also associated to the iron-magnesium minerals, c. Mt crystal associated to Bt partially chloritized and Cl. d. Mt crystals (light gray) associated to trellis (T) Ilm (dark gray lamellae), patch (P) Ilm (irregular portions on the Mt border) and composite (C) Ilm (subedric crystal) 

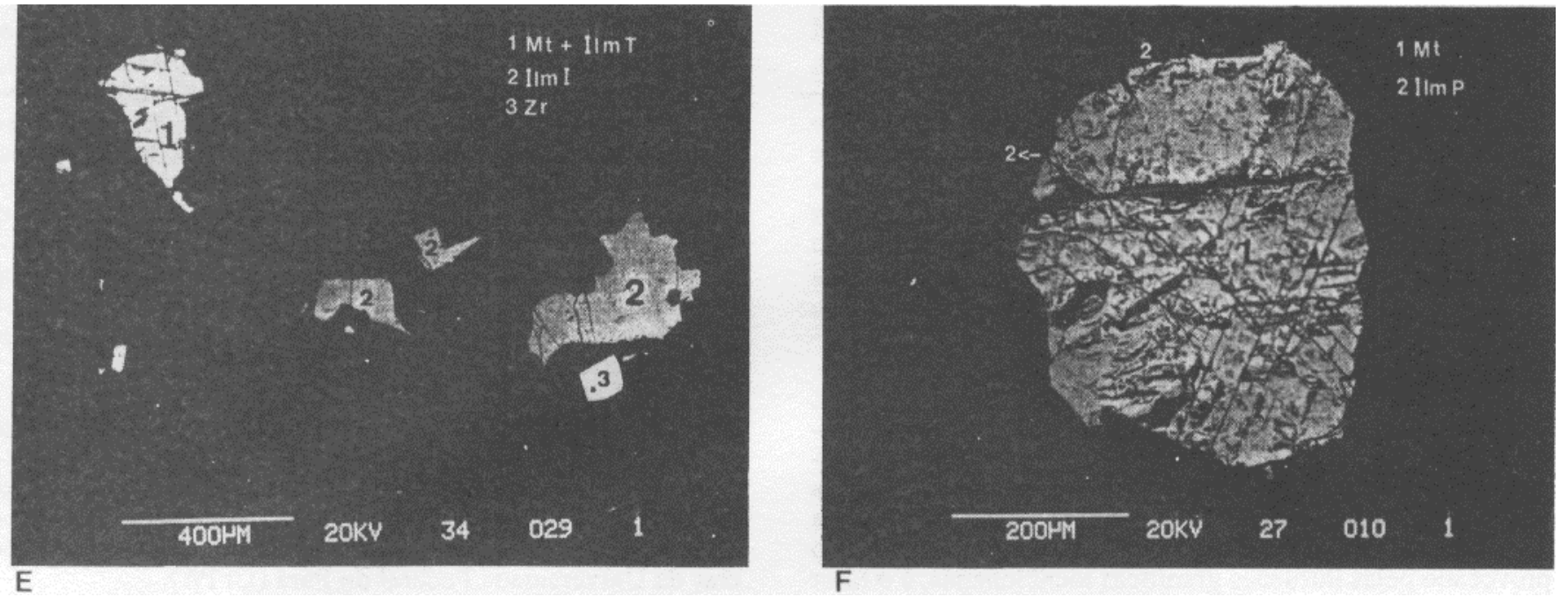

Prancha 1 - e. Cristal de Mt (cinza-claro) intercrescido com Ilm trellis (T, cinza-escuro), cristais individuais de Il (I, cinza-escuro) e Zr (branco), f. Cristal de Mt intercrescido com lamela de Ilm trellis (T, cinza-escuro) e Ilm patch (P) em sua borda (cinza-escuro)

Plate 1 - e. Mt-Ilm intergrowth (Mt + Ilm T), individual (I) Ilm crystals (dark gray), and zircon (white), f. Mt crystal with a trellis (T) Ilm lamella (dark gray), associated to patch (P) Ilm (dark gray)

lores de SM relativamente baixos, que parecem ser característicos dessa unidade, ocorrem nas outras porções do batólito e correspondem, principalmente, a HBGd e biotita granodioritos e, mais raramente, a BHGd. Este tipo de comportamento magnético indica que, na região próxima ao contato desse batólito com as intrusões graníticas citadas anteriormente, deva ter ocorrido, como decorrência da recristalização metamórfíca provocada pelo efeito térmico, a neoformação de magnetita. O conteúdo de hornblenda próximo ao contato também é mais elevado, o que sugere formação de pelo menos parte do conteúdo desse mineral durante esse evento metamórfico de contato. Também no caso do Metatonalito Gnáissico Arco Verde (Althoff et al. 1991) de idade arqueana, foram obtidos valores mais elevados de SM em amostras de áreas próximas ao seu contato com os granitos anorogênicos do Proterozóico Musa e Marajoara (Magalhães et al. 1994). Speer (1981) também observou a variação do conteúdo de magnetita, e conseqüentemente da intensidade magnética, em rochas metapelíticas próximas do contato com um plúton granítico.

Dentre os minerais opacos descritos neste granitóide, destaca-se apenas magnetita, uma vez que pirita ocorre raramente e a martitização não é uma transformação de grande expressividade nessas rochas (Tab. 2).

As condições de $\mathrm{f}_{\mathrm{O} 2}$ em que se formou o batólito de Rio Maria é uma questão complexa, haja vista o evento metamórfico nas condições fácies xisto-verde ter afetado as suas rochas, bem como o evento metamórfico de contato. Contudo, fugacidades de oxigênio próximas àquelas do tampão NNO podem ter existido durante a geração desse batólito, como sugere a associação titanita-magnetita-quartzo, que parece ter sido estável também durante o estágio ígneo. Rumble (1981) sugere $\mathrm{f}_{\mathrm{O} 2}$ entre às do tampão HM e NNO para rochas que sofreram metamorfismo de baixo grau. Contudo, na auréola de contato, o conteúdo mais elevado de magnetita e hornblenda poderia ser explicado por um aumento relativo das condições de $\mathrm{f}_{\mathrm{O} 2}$ durante o evento metamórfico de contato, conforme propõe a seguinte reação (adaptada de Grant 1985):

Biotita + Hornblenda $\pm \mathrm{SiO}_{2} \pm \mathrm{O}_{2}->$ K-feldspato + Hornblenda \pm Magnetita
Buddington \& Lindsley (1964) sugerem que condições de $\mathrm{f}_{\mathrm{O} 2}$ pré-metamórficas devem ser tamponadas, sendo modificadas apenas quando houver a total recristalização dos minerais de óxidos. É possível, que o estudo da composição química dos minerais desse batólito, permita compreender as condições de $\mathrm{f}_{\mathrm{O} 2}$ reinantes durante o evento metamórfico de contato.

Concluindo, acredita-se que o tipo de comportamento magnético desse grupo de granitóides é decorrência dos processos complexos que ocorreram durante a evolução dessas rochas, processos que envolveram os minerais opacos, seja transformando-os como no caso do Gcg, seja levando a sua neoformação tal como observado nas zonas de contato do GDrm.

CONCLUSÕES O estudo de SM de granitóides da Amazônia permitiu separar rochas com histórias evolutivas diferentes.

Os valores reduzidos de SM dos granitos estaníferos devem ser conseqüência de condições de $\mathrm{f}_{\mathrm{O} 2}$ menos oxidantes do que aquelas mais freqüentemente observadas em magmas graníticos não enriquecidos em Sn (Taylor \& Wall 1992), uma vez que tais condições devem ter sido determinantes na formação da assembléia mineral observa$\mathrm{da}$, inclusive das fases minerais opacas. Da mesma forma, tanto as transformações tardi a pós-magmáticas, as quais devem ter provocado a desestabilização de magnetita, como os líquidos evoluídos a partir dos quais essas rochas foram geradas, podem acarretar os baixos valores de SM observados.

Os granitos Musa e Jamon são rochas que apresentam conteúdo expressivo de magnetita, como revelam os seus valores de SM relativamente elevados. As condições de $\mathrm{f}_{\mathrm{O} 2}$, em que se formaram esses granitóides, situam-se próximas às dos tampões NNO e HITMQ como sugerem a associação mineral titanita-magnetita-quartzo (Wones 1989), a paragênese de opacos semelhante a descrita em granitos do tipo I (Whalen \& Chappell 1988) e os dados de $\mathrm{f}_{\mathrm{O} 2}$ obtidos para o Gj (Dali' Agnol et al. 1995).

O maciço Cigano, apesar de ser um granito com magnetita, apresenta comportamento magnético diferente dos ma- 
ciços Musa e Jamon. A distribuição de SM desse maciço não é uniforme para uma mesma fácies e os seus valores de SM são muito variáveis, ocorrendo desde valores muito baixos, sem similares nos maciços Musa e Jamon, até valores relativamente elevados, comparáveis aos das fácies hololeucocráticas desses granitos. As transformações dos cristais de magnetita (martitização), bem como razões mais expressivas de $\mathrm{Ilm} / \mathrm{Mt}$, podem ser apresentadas como alguns dos fatores que permitiram o tipo de comportamento magnético observado no $\mathrm{Gcg}$, refletindo as condições de $\mathrm{f}_{\mathrm{O} 2}$ que prevaleceram durante a formação desse maciço e que foram, possivelmente, inferiores às do tampão NNO, mas superiores àquelas do tampão FMQ.

O Granodiorito Rio Maria, do ponto de vista magnético, assemelha-se ao Gcg. Nesse granitóide, SM elevada concentra-se nas porções próximas do contato com intrusões graníticas proterozóicas ( $\mathrm{Gmu}$ e $\mathrm{Gj}$ ), ao passo que valores baixos são dominantes nas outras porções do batólito. Logo, a neoformação de magnetita, decorrente do efeito térmico provocado pelas intrusões graníticas mencionadas, é o fator determinante para a elevação da SM nas porções de contato. As condições de $\mathrm{f}_{\mathrm{O} 2}$ existentes durante o evento metamórfico regional não devem ter sido muito diferentes daquelas reinantes durante a formação desse batólito (Buddington \& Lindsley 1964, Grant 1985). Entretanto, durante o metamorfismo de contato, deve ter ocorrido um aumento relativo da $\mathrm{f}_{\mathrm{O} 2}$.

As diferenças observadas entre os comportamentos magnéticos dos granitóides estudados mostram a importância da utilização de dados de SM em estudos de cunho petrológico e metalogenético. Esses dados permitiram a separação de granitos com magnetita formados em condições de $\mathrm{f}_{\mathrm{O} 2}$ relativamente elevadas (granitos Musa e Jamon) do Granito Cigano também portador de magnetita, porém gerado em condições de $\mathrm{f}_{\mathrm{O} 2}$ comparativamente inferiores. Eles levaram também à caracterização de uma auréola de contato no Granodiorito Rio Maria e à separação de granitos estaníferos em um grupo com comportamento magnético específico, em que as fácies mais transformadas e especializadas em Sn apresentam valores de SM distintamente mais reduzidos. Ressalta-se, assim, a importância da interação de dados magnéticos (SM), petrográficos, incluindo o estudo das fases minerais denominadas opacas, e geoquímicos.

AGRADECIMENTOS O suporte financeiro para a execução desse trabalho foi fornecido pelo Conselho Nacional de Desenvolvimento Científico e Tecnológico (CNPq) e pelo Projeto Petrologia dos Granitóides da Amazônia Oriental (FINEP - PADCT), desenvolvido no Centro de Geociências da Universidade Federal do Pará (UFPA).

Gostaríamos de agradecer à Companhia Brasileira de Metalurgia e Mineração (CBMM), em particular a B. Riffel, ao Centre de Recherches Pétrographiques et Géochimiques (CRPG - CNRS), a A. Kohler e a J. Gorau do Service Comune de Microanalyses da Université Nancy I pelo apoio na obtenção de informações e imagens em microscópio eletrônico de varredura (MEV); a Jorge S. Bettencourt (Universidade de São Paulo, USP) pelas amostras, lâminas e informações geológicas sobre o Granito Pedra Branca.

\section{REFERÊNCIAS BIBLIOGRÁFICAS}

ALTHOFF, F. J.; DALL'AGNOL, R. \& SOUZA, Z. S. 1991. Região de Marajoara - SE do Pará: prolongamento dos terrenos arqueanos de Rio Maria ou retrabalhamento? In: SIMP. GEOL. AMAZ., 3, Belém, 1991. Anais... Belém, SBG. p. 130-141.

BALSLEY, J. R. \& BUDDINGTON, A. F. 1958. Iron-titanium oxide minerals, rocks and aeromagnetics anomalies of the Adirondack area, New York. Econ. Geol., 53(7): 777-805.

BARROS, C. E. M., DALL'AGNOL, R.; LAFON, J.-M.; TEIXEIRA, N. P. \& RIBEIRO, J. W. 1992. Geologia e geocronologia Rb-Sr do Gnaisse Estrela, Curionópolis, PA. Boi. Mus. Par. Emílio Goeldi, 4: 85-104.

BUDDINGTON, A.F. \& LINDSLEY, D.H. 1964. Iron-titanium oxide minerals and synthetic equivalents. J. Petr., 5(2): 310-357.

COLLINSON, D. W. 1983. Methods in rock magnetism and paleomagnetism (techniques and interpretation). $1^{\text {st }}$ ed. New York, Chapman and Hall, $503 \mathrm{p}$.

CRISS, R.E. \& CHAMPION, D.E. 1984. Magnetic properties of granitic rocks from southern half of Idaho Batholith: influences of hydrothermal alteration and implications for aeromagnetic interpretation. J. Geophys. Res., 89(B8):7061-7076.

DALL'AGNOL, R.; BETTENCOURT, J. S.; JORGE-JOÃO, X. S.; MEDEIROS, H.; COSTI, H. T. \& MACAMBIRA, M. J. B. 1987. Granitogenesis in the Northern Brazilian region: a review. Rev. Bras. Geoc., 17: 382-403.

DALL'AGNOL, R.; LAFON, J.-M. \& MACAMBIRA, M. J. B. 1994. Proterozoic anorogenic magmatism in the Central Amazonian Province, Amazonian Craton: geochronological, petrological and geochemical aspects. Mineral. Petrol., 50: 113-138.

DALUAGNOL, R.; PICHAVANT, M. \& CHAMPENOIS, M. 1995. Opaque mineralogy and magmatic evolution of the Jamon Proterozoic anorogenic magnetite granite. Eastern Amazony, Brazil. In: SYMPOSIUM ON RAPAKIVI GRANITES AND RELATED ROCKS, Belém, 1995. Abstracts volume... Belém, IGCP (Project $315)$, p. $24-25$

DALL'AGNOL, R.; SAUCK, W.A. \& GONCALEZ, M.G.B. 1988. Suscetibilidade magnética em granitóides da Amazônia: um estudo preliminar. In: CONGR. BRAS. GEOL., 35, Belém, 1988. Anais... Belém, SBG, v.3, p.1164-1173.

DOCEGEO (Distrito Amazônia). 1988. Revisão litoestratigráfica da Província Mineral de Carajás. In: CONGR. BRÂS. GEOL., 35, Belém, 1988. Província Mineral de Carajás litoestratigrafia e principais depósitos minerais. Anexo aos anais. Belém, CVRD - SBG. p. 11-54.
FROST, B. R. 1991. Magnetic petrology: factors that control the occurrence of magnetite in crustal rocks. In: LINDSLEY, D. H. ed. Oxide minerals: petrologic and magnetic significance. Washington. Miner. Soc. Am., p. 489-509.

GASTAL, M.C.P. 1988. Magmatismo ácido-intermediário do Proterozóico Médio na região de Rio Maria, SE do Pará: discussão quanto à tipologia. In: CONGR. BRÁS. GEOL., 35, Belém, 1988. Anais... Belém, SBG. v.3. p.1147-1163.

GONCALEZ, M. G. B.; DALL'AGNOL, R.; VIEIRA, E. A. P.; MACAMBIRA, M. J. B. \& SENA, N. D. 1988. Geologia do macico anorogênico Cigano, Vale do Rio Parauapebas - PA. In: CONGR. BRÁS. GEOL., 35, Belém, 1988. Anais... Belém, SBG. v. 3, p. $1132-1146$

GRANT, F.S. 1985. Aeromagnetics, geology and ore environments. I. Magnetite in igneous, sedimentary and metamorphic rocks: an overview, Geoexploration, 23:303-333.

HAGGERTY, S. E. 1981a. Opaque mineral oxides in basalts. In: RUMBLE HI, D. Oxide minerals. 2"* ed. Washington. Miner. Soc. Am., Hgl-HglOO

HAGGERTY, S. E. 1981b. Opaque mineral oxides in terrestrial igneous rocks. In: RUMBLE III, D. Oxide minerals. $2^{\text {nd }}$ ed. Washington. Miner. Soc. Am., Hgl01-Hg300.

HATTORI, K. 1987. Magnetic felsic intrusions associated with Canadian Archean gold deposits. Geology, 15:1107-1111.

HENKEL, H. 1976. Studies of density and magnetic properties of rocks from northern Sweden. Pure Appl. Geophys., 114:235-249.

HIRATA, W. K.; RIGON, J. C; KADEKARU, K.; CORDEIRO, A. A. C. \& MEIRELES, E. M. 1982. Geologia regional da Província Mineral de Carajás. In: SIMP. GEOL. AMAZ., 1, Belém, 1982. Anais... Belém, SBG. v. 1, p. 100-110.

ISHIHARA, S. 1977. The magnetite-series and ilmenite-series granitic rocks. Mining Geology, 27:293-305.

ISHIHARA, S. 1981. The granitoid series and mineralization. In: SKINNER. B. J. ed. Economic Geology Seventy-fifth Anniversary-

volume. Lancaster. Econ. Geol., p. 458-484.

LAPOINTE, P.; CHOMYN, B. A.; MORRIS, W. A. \& COLES, R. L. 1984. Significance of magnetic susceptibility measurements from Lac $\mathrm{du}$ Bonnet Batholith, Manitoba, Canada. Geoexploration, 22:217-229.

LAPOINTE, P.; MORRIS, W. A. \& HARDING, K.L. 1986. Interpretation of magnetic susceptibility: a new approach to geophysical evaluation of the degree of rock alteration. Can. J. Earth Sci. 23:393-401. 
MACAMBIRA, E. M. B. \& VALE, A. G. no prelo. Programa Grande Carajás, Folha SB-22-Y-B São Felix do Xingu. Belém. $\mathrm{DNPM} / \mathrm{CPRM}$.

MACHADO, N.; LINDENMAYER, D \& LINDENMAYER, Z. 1988. Geocronologia U-Pb da Província Metalogenética de Carajás, Pará: resultados preliminares. In: CONGR. LAT. AMER. GEOL., 7, Belém, 1988. Anais... Belém, SBG, v.1, p. 339-347.

MAGALHÃES, M.S. 1991. Minerais opacos e susceptibilidade magnética de granitóides da Amazônia Oriental: implicações petrológicas. Belém, 274p. (Tese de Mestrado. UFPA - Centro de Geociências).

MAGALHÃES, M.S. \& DALL'AGNOL, R. 1991. Considerações petrológicas baseadas em estudos de minerais opacos e suscetibilidade magnética no Granodiorito Rio Maria (região de Rio Maria - sudeste do Pará). In: SIMP. GEOL. AMAZ., 3, Belém, 1991. Anais... Belém, SBG. p. $70-84$

MAGALHÂES, M. S. \& DALL'AGNOL, R. 1992. Estudos de minerais opacos e suscetibilidade magnética nos granitos Musa e Jamon (região de Ris Maria - SE do Pará) e suas implicações petrológicas. Rev. Bras. Geoc., 22(2): 184-197.

MAGALHÃES, M. S., FIGUEIREDO, M.A.B.M. \& ALTHOFF, RJ. 1994. Comportamento magnético do íbnalitp Arco Verde e do Granito Guarantã, Rio Maria, Pará: suscetibilidade magnética e minerais opacos. In: SIMP. GEOL. AMAZ., 4, Belém, 1994. Resumos Expandidos... Belém, SBG.

MEDEIROS, H. \& DALL'AGNOL, R. 1988. Petrologia da porção leste do batólito granodiorítico Rio Maria, sudeste do Pará. In: CONGR. BRĂS. GEOL., 35, Belém, 1988. Anais... Belém, SBG. v. 3, p. $1488-1499$

MOONEY, H.M. \& BLEIFUSS, R. 1953. Magnetic susceptibility measurements in Minnesota, part II, analysis of field results. Geophysics, 18:383-393.
SOUZA, Z.S.; MEDEIROS, H.; ALTHOFF, F.J. \& DALL'AGNOL, R. 1990. Geologia do terreno granito-"greenstone" Arqueano da região de Rio Maria, sudeste do Pará. In: CONGR. BRAS. GEOL., 36, Natal, 1990. Anais... Natal, SBG. v.6, p. 2913-1928.

SPEER, J. A. 1981. The nature and magnetic expression of isograds in the contact aureole of the Liberty Hill Pluton, South Carolina: summary. Geol. Soc. Am. Bull., 92:603-609.

SPENCER, K. J. \& LINDSLEY, D. H. 1981. A solution model for coexisting iron-titanium oxides. Am. Mineral., 66:1189-1201.

RUMBLE III, D. 1981. Oxide minerals in metamorphic rocks. In: RUMBLE III, D. ed. Oxide minerals. $2^{\text {nd }}$ ed. Washington. Miner. Soc. Am., p. R1-R23.

TAYLOR, J. R. \& WALL, V. J. 1992. The behavior of tin in granitic magmas. Econ. Geol., 87:403-420.

TEIXEIRA, N. P. \& DALL'AGNOL, R. 1991. Geologia do maciço granítico Antônio Vicente.Boi. Mus. Par. Emillio Goeldi, 3:45-73.

TEIXEIRA, W; TASSINARI, C. C. G.; CORDANI, U. G. \& KAWASHITA K. 1989. A review of the geochronology of the Amazonian Craton: tectonic implications.Precambrian Res., 42:213-227.

WASILEWSKI, P. \& WARNER, R. D. 1988. Magnetic petrology of deep crustal rocks - Ivrea Zone, Italy. Earth Planet. Sci. Lett. 87:347-361.

WHALEN, J.B. \& CHAPPELL, B.W. 1988. Opaque mineralogy and mafic mineral chemistry of I- and S-type granites of the Lachlan fold belt, southeast Australia. Am. Mineral., 73:281-296.

WONES, D.R. 1989. Significance of the assemblage titanite + magnetite + quartz in granitic rocks. Am. Mineral., 74:744-749.

MANUSCRITO A808 Recebido em 13 de dezembro de 1993 Revisão do autor em 11 de maio de 1995 Revisão aceita em 8 de janeiro de 1996 